\title{
A modernização da administração pública brasileira nos últimos 40 anos*
}

\author{
Paulo Roberto Motta**
}

SUMÁRIO: 1. Introdução; 2. Limites da formalidade institucional; 3. A era pós-Constituição: a redemocratização e as novas conquistas constitucionais; 4. Conclusão.

SUMMARY: 1. Introduction; 2. Limitations of institutional formality; 3. The post-Constitution era: redemocratization and the new constitutional feats; 4. Conclusion.

PalaVRas-Chave: modernização administrativa; administração pública; reforma administrativa.

KEY WORDS: administrative modernization; public administration; administrative reform.

Nos últimos 40 anos, a administração pública brasileira passou por grandes transformações, sobretudo como parte do trânsito para a democracia. Desenvolveram-se novas práticas e expectativas de modernização, mas muitas de suas características tradicionais não foram removidas. A modernização efetiva somente ocorrerá com reformas que redistribuam os recursos de poder e alterem os canais de comunicação entre o público e sua administração. Novos espaços, regras e estruturas administrativas são necessários para garantir maior autenticidade na representação política.

Brazilian public administration modernization in the last 40 years During the last 40 years, the Brazilian public administration underwent great transformations, mostly as part of its passage toward democracy. New

* Artigo recebido e aceito em jun. 2007.

** PhD e mestre em administração pública pela University of North Carolina (EUA). Professor titular da Ebape/FGV, professor visitante da Universidade de Manchester (Inglaterra), da HEC Management (França), da Universidade de Macau (China), do Instituto Nacional de Administração (Portugal) e da Otto-von-Guericke-Universidade Magdeburg (Alemanha). Endereço: Praia de Botafogo, 190, sala 527 - CEP 22250-900, Rio de Janeiro, RJ. E-mail:paulmotta@fgv.br. 


\begin{abstract}
practices and modernization expectations were developed, but many of its traditional characteristics were not removed. Real modernization will only happen with reforms that will redistribute the power resources and change the communication channels between the public and its administration. New spaces, rules and administrative structures are needed to guarantee more authentic political representation.
\end{abstract}

\title{
1. Introdução
}

Nas últimas décadas, a administração pública brasileira passou por grandes transformações, sobretudo como parte do trânsito para a democracia. Desenvolveram-se novas práticas e expectativas de modernização, mas muitas de suas características tradicionais não foram removidas.

A Revista de Administração Pública (RAP) surgiu numa época em que a administração pública possuía forte presença na sociedade, não só por causa das funções de controle não-democrático, mas também porque se procurava o desenvolvimento com base em projetos públicos de grande escala. Pensava-se que a própria expansão do Estado fosse suficiente para garantir mais e melhores serviços, bem como maior acesso comunitário e eqüidade nas decisões distributivas. Nesse sentido, nos primeiros 20 anos da $R A P$, a administração pública teve crescimento considerável.

No entanto, a experiência histórica revelou que simplesmente expandir as atividades do Estado e as funções serviu menos ao propósito de alcançar maior eqüidade e eficácia na administração pública do que ao desenvolvimento de formas de inserção de novos grupos preferenciais.

Nessa época descrevia-se a administração pública brasileira pelos seus aspectos mais patrimonialistas e paternalistas. Viam-se as suas relações com a sociedade como extremamente frágeis. Na verdade, a administração pública desenvolveu-se como um dos grandes instrumentos para a manutenção do poder tradicional, e carregava fortes características desse poder. A forma de organização e gestão obedecia menos a critérios técnicos racionais e democráticos para a prestação de serviços e mais a sistemas de loteamento político, para manter coalizões de poder e atender a grupos preferenciais.

Em grande parte, a expansão do Estado se fez sem alterar substancialmente suas relações com a sociedade. Por ter ainda alicerces frágeis na sociedade, o Estado brasileiro, como organização, consiste ainda em uma superestrutura que flutua sobre os cidadãos. 


\section{Limites da formalidade institucional}

A formalidade institucional possui limites para explicar a evolução da administração pública brasileira. Fatores de informalidade prevalecem e determinam muito do que se decide e se executa na administração brasileira, compreendendo seus três níveis de governo: federal, estadual e municipal. Por estarem inseridos na cultura sociopolítica do país, esses fatores não são facilmente removíveis ou contornados por meio de reformas administrativas de lógica racional burocrática.

Fatores de informalidade continuam a chamar a atenção dos estudiosos e analistas da gestão pública, além de ser retratados cotidianamente na mídia como práticas comuns de gestão. São exemplos marcantes o personalismo paternalista e a presença de grupos preferenciais que se organizam por fora das instituições, mas que procuram manter fortes relações com o Estado. Esses fatores distanciam os cidadãos da gestão pública, desenvolvendo a síndrome nós-eles.

\section{O personalismo}

O personalismo - normalmente descrito como prevalecente no mundo latino-americano - faz ver o poder como centrado na figura de um líder, um dirigente, e não como o resultado da gestão de recursos inerente a estruturas formais. Por ser um fator cultural, está presente na gestão tanto pública quanto privada. Na realidade, origina-se na desigualdade social e se desenvolve pelas práticas de exclusão e pelo cultivo do elitismo, ou seja, a crença de que algumas pessoas são naturalmente mais capazes do que outras. Assim, o acesso a posições de comando e direção é antes de tudo influenciado pelas condições de diferenciação social. Facilmente se desenvolve o autoritarismo hierárquico social, centrado no personalismo: certas pessoas devem ser diferenciadas em seleção e privilégios para posições de comando. Ainda, por ser um fator cultural, é mais facilmente aceito e praticado. A maioria das pessoas, subordinadas nas organizações de trabalho - públicas ou privadas —, sentese presa às suas condições sociais e julga ser inútil ou fora de seu alcance ter iniciativa, ambição ou ilusão de que a ordem social e administrativa poderia ser diferente. Nas sociedades, naturalmente desiguais, prospera a crença de que as pessoas devem ser tratadas desigualmente, e os privilégios são aceitos, praticados e reconhecidos como direitos. 
No entanto, o personalismo elitista concorre para enfraquecer substancialmente as instituições. Estas existem em função das pessoas que as dirigem, e a mudança da pessoa no topo muda profundamente políticas e compromissos institucionais.

Na administração pública, dirigentes, normalmente prepostos de líderes políticos, tendem a inserir suas opções pessoais como fator diferenciador. Desprezam, assim, não só o racionalmente instituído como também opções e conquistas de seus antecessores. A descontinuidade é justificada como necessária à inovação. Na verdade, resulta mais em garantir acesso a novos grupos de poder e ressaltar a liderança de uma pessoa e menos em modernizar a gestão. Compromissos formais institucionalmente estabelecidos necessitam ser renegociados a cada novo dirigente. Na verdade, não há contratos com instituições, mas com pessoas. O personalismo fragiliza as instituições públicas, deixando-as altamente vulneráveis e dependentes da pessoa de um único dirigente.

A administração pública era em grande parte dominada por grupos preferenciais que visavam garantir seus interesses e a proteção mútua de seus membros. Apesar da modernização, muitos desses grupos ainda se aglutinam no aparato estatal em busca de recursos para garantir sua sobrevivência. Inserem-se em órgãos administrativos por meios formais - ocupação de cargos de direção —, mas também informalmente, por meio de redes de apoio e de interação ligadas por laços de lealdade. Procuram o acesso a recursos públicos para reforçar a lealdade política de base e preservar a liderança sobre determinados setores da comunidade. Esses recursos são utilizados para satisfazer não somente interesses políticos de poder como também interesses sociais e particulares. Tais grupos dominam máquinas partidárias para evitar que alternativas de política pública, contrárias aos seus interesses, sejam consideradas no processo decisório governamental. Controlam estruturas burocráticas de governo para garantir, durante longos períodos, o uso preferencial de grandes fatias do orçamento público.

O uso de recursos públicos é o mecanismo básico de preservação do poder: são utilizados menos para atender a demandas e necessidades reais da comunidade e mais para a troca de favores e os interesses particulares do grupo. Como a lealdade aos membros do grupo é maior do que à instituição pública, tais grupos são capazes de manter a coalizão a qualquer custo, inclusive às expensas do aumento dos gastos governamentais.

Normalmente, esses grupos preferem dominar as áreas sociais por serem mais diretamente ligadas às maiores demandas da população. Setores sociais são privilegiados para o exercício do assistencialismo paternalista; propiciam ao líder do grupo o exercício da "bondade" por meio da concessão de benefícios e favores com o dinheiro público. Assim, os líderes políticos e diri- 
gentes públicos podem favorecer segmentos da população sob sua influência, fazendo-os crer que o benefício concedido é uma concessão pessoal do líder, e não um direito individual ou um valor de cidadania. $\mathrm{O}$ resultado final é o reforço do poder e da liderança tradicionais.

Vale ressaltar que esses grupos que se inserem e dominam setores da administração pública não são pequenos grupos de aproveitadores ou perturbadores marginais da ordem administrativa; são grupos organizados e institucionalizados dentro do sistema político. Transformam o Estado num campo minado de lutas políticas, mas mantidas nos limites das estruturas formais para não ferir a estabilidade e legitimidade do sistema. Por esse motivo, as discórdias são bem toleradas e, de preferência, confinadas à arena política predeterminada, que é o Estado.

Visto segundo uma lógica da gestão moderna, o sistema administrativo pode parecer altamente irracional, mas para os grupos preferenciais que dele se servem representa um sistema lógico e altamente racional. Baseia-se em valores e práticas tradicionais: assenta grande parte do poder político no distanciamento autoritário, no paternalismo e no exercício da bondade.

Eesses grupos não criam rupturas nas dimensões formais da administração pública. Procuram seguir os passos formais, mas repletos de acomodação, concessões e opções de natureza paternalista. Por terem lealdade quase nula à instituição pública, circulam facilmente entre as repartições, procurando obter melhores benefícios, indiferentes aos danos que causam, tanto ao interesse quanto ao orçamento público.

Os cidadãos passam a ser receptores passivos da bondade. Ao receber benefícios, vêem seus líderes e dirigentes como os mais bondosos e por isso merecedores de reconhecimento e apoio político.

\section{Síndrome nós-eles}

Da mesma forma que os governantes eleitos, os administradores públicos são vistos como pessoas especiais distantes da sociedade, menos voltadas para o interesse público e mais autocentradas.

Dificuldades oriundas da discriminação contra a cidadania — deficiência nos serviços de saúde, evasão escolar, crianças abandonadas, insegurança pública e pobreza - fazem a maioria ver seus representantes e funcionários como pessoas despreocupadas com seus problemas. O relacionamento clienteorganização pública se faz segundo uma síndrome nós-eles. Pelo controle político, centralização excessiva e paternalismo, a população brasileira aprendeu 
a conviver com a submissão, a alienação e o descrédito em relação à administração pública.

A síndrome nós-eles se espalha facilmente. Parcelas substanciais da população tendem a ver seus dirigentes e representantes políticos como outro tipo ou classe de gente: nós somos nós e eles são eles.

\section{A era pós-Constituição: a redemocratização e as novas conquistas constitucionais}

Com a redemocratização, a inspiração neoliberal e as referências das inovações oriundas de países mais avançados, os movimentos de reforma procuravam centrar-se nas especificidades das diversas organizações públicas, à semelhança das mudanças na área privada. A perspectiva básica era a eficiência e capacidade de resposta da administração pública e melhora da gerência pública. Passou-se a questionar o tradicionalismo da administração pública, mas incorporando os fundamentos democráticos implantados na nova Constituição, como a subordinação da administração pública a mandatos políticos conquistados em eleições democráticas.

Em períodos não-democráticos, as tentativas de aparência tecnocrática ofuscaram muitos dos problemas de embates políticos, não porque deixassem de existir, mas porque havia sempre um lado repressor.

Com as novas inspirações ideológicas, começou-se a delinear a idéia de que os governos não poderiam sozinhos conduzir ao progresso. O desenvolvimento passou a ser visto como algo complexo e gigantesco, e as máquinas administrativas tradicionais não como fator de modernização, mas obstáculos ao progresso. Surgiram movimentos significativos, em muitos países e apoiados por entidades internacionais, para proclamar a descrença nas possibilidades da administração pública de conduzir o desenvolvimento.

Reduzir o tamanho do Estado e modernizar a administração pública tornaram-se pontos importantes de uma nova agenda política. Ao contrário das experiências anteriores, essa modernização se inspirou fortemente nos modelos de gestão privada, considerados superiores e mais eficazes.

Assim, as principais mudanças seriam transferir funções estatais para a área privada e as restantes seriam administradas com formas o mais próximo possível das praticadas nas empresas privadas.

Tendo a representação democrática como premissa, tentou-se valorizar as técnicas administrativas e a competência neutra dos servidores, presumindo sempre a sua ação por delegação política e não por autonomia própria. A administração eficiente seria conseqüência natural de instrumentos gerenciais, 
como estruturas e códigos de procedimentos adequados e boas regras orçamentárias e gestão de pessoal. Pela falta de eficiência, culpavam-se a inadequação das estruturas e dos procedimentos e a inabilidade dos próprios servidores. Ajustes administrativos seriam feitos de acordo com novos propósitos políticos, adquiridos em eleições, ou com novas tecnologias administrativas. As reformas preservavam as estruturas organizacionais, favoreciam a rigidez dos códigos administrativos, e algumas propostas mais audaciosas propunham maior descentralização e autonomia organizacional. Entretanto, não se questionava fundamentalmente a administração pública, senão sua ineficiência ou iniqüidade.

Em grande parte, essas reformas colocavam em causa a própria viabilidade da administração pública como condutora de eficiência ou de eficácia na gestão de serviços e na ação redistributiva. Os novos modelos procuram transformar e introduzir na gestão pública o estilo privado. Além de ampliarem a importação de técnicas típicas da área privada, propõem sempre com grande ênfase eliminação, privatização e terceirização de serviços.

Nos países em desenvolvimento, como o Brasil, as idéias sobre reformar a administração, com premissas de radicalismo e promessas de eficiência imediata, são sempre atraentes, dadas as dificuldades que os cidadãos enfrentam em tratar de seus interesses em qualquer organização pública. Ao entrar em contato com uma repartição pública, a maioria dos cidadãos experimenta uma história de relativo descaso e má qualidade no atendimento, sobretudo na área social. Para essas pessoas, a ineficiência no serviço é um sintoma de iniqüidade social, já que os mais afortunados normalmente dispõem de outros meios.

Ao imitar a gestão privada, as propostas contemporâneas assumem a singularidade do cliente e suas demandas como fundamentais na gestão pública. Por presumirem a validade universal do management e, portanto, sua aplicabilidade igualmente às organizações públicas e privadas, vêem a reforma como uma simples questão de modernização gerencial. Antes de planejar suas ações ou oferta de serviços, as organizações públicas devem conhecer as demandas de sua clientela. A organização pública existe para servir o indivíduo: deve centralizar suas ações na demanda do cliente e na sua escolha. Como no mercado, cliente é categoria primordial, e deve ser considerado em todas as instâncias.

Essa ideologia veio contaminada e reforçada pelos valores dos países mais avançados, onde o individualismo fundamentado na igualdade das oportunidades constitui uma prática social comum. Por isso esses modelos centramse mais no indivíduo (clientes e funcionários) e menos no contexto. A ideologia liberal centrada no indivíduo valoriza a iniciativa, o espírito empreendedor e o 
desempenho e realização individuais. As pessoas se singularizam perante os outros pelo seu desempenho e merecem ser tratadas diferentemente pelas desigualdades conquistadas. Assim, métodos de avaliação de desempenho individual e organizacional passaram a ser propostos com maior vigor.

Tais idéias de reforma não progrediram com a ênfase desejada porque esbarraram em fatores históricos tradicionais ainda prevalecentes e que não se coadunam com práticas neoliberais.

Ainda prevalece e se reforça a visão de ser a administração pública responsável por reduzir a desigualdade social tanto por medidas desenvolvimentistas quanto por programas sociais compensatórios.

Na prática neoliberal de países mais avançados, a gestão pública deve agir no sentido de manter a igualdade perante a lei e de garantir oportunidades iguais, salvo nos casos em que as chances não são claramente iguais. Programas sociais se justificam mais facilmente pela desigualdade de oportunidades do que pela compensação de diferenças de desempenho.

\section{Conclusão}

A permanência de fortes relações com grupos preferenciais faz a administração brasileira ser retratada ainda como de grande base patrimonialista. As relações patrimoniais contradizem não somente as possibilidades de uma administração modernizada no sentido mais amplo do interesse público como também as práticas liberais tão proclamadas como a opção política dos últimos anos.

Como a administração pública e a cultura tradicional são ainda bastante interligadas, apesar dos progressos na modernização institucional, os relatos cotidianos na mídia ainda demonstram forte ligação da coisa pública com interesses privados de grupos preferenciais.

O mundo das relações informais é fundamentalmente baseado no aspecto político tradicional, mas se ampliou pelo reforço de aspectos psicológicos culturais, como a maior descrença dos cidadãos na representação política e, em decorrência, nos órgãos da administração pública. Com a crença reduzida nas instituições e na formalidade burocrática, buscam-se o informal e novas instituições da sociedade, como associações de usuários, cidadãos e ONGs, para proteger interesses e direitos. Essas organizações e associações comunitárias diversas procuram contornar as instituições públicas existentes tentando assumir tarefas antes vistas como exclusivas do Estado e mesmo influenciar a gestão de órgãos públicos e a representatividade política. 
Favorecidas pela consciência popular sobre a ineficácia da administração pública em relação à eqüidade política, econômica e social, essas novas associações e organizações agregam um espírito de proteção de interesses da maioria para contrapor-se à crença de que as instituições formais defendem e protegem interesses de uns poucos.

Na verdade, essas novas instâncias também agem no sentido de penetrar nas organizações públicas para defender interesses de suas clientelas, por serem esses interesses julgados legítimos, mas desprezados pelas elites administrativas. Praticam também a informalidade nas relações pessoais para atingir seus objetivos. Mesmo se aceitando uma contraposição legítima de fazer prevalecerem direitos não-reconhecidos, a prática da informalidade excessiva, inclusive nesses casos, concorre para enfraquecer as instituições democráticas de representação política e de ação administrativa.

Assim, a administração pública brasileira ainda carrega tradições seculares de características semifeudais e age como um instrumento de manutenção do poder tradicional. Apesar do progresso em muitas instâncias de governo, as formas de ação obedecem menos a razões técnico-racionais e mais a critérios de loteamento político, para manter coalizões de poder e para atender a objetivos de grupos preferenciais.

No Brasil contemporâneo, a democratização e os novos processos eleitorais e os dispositivos constitucionais ajudam a levantar ou reacender expectativas sobre mais e melhores serviços, o que, aos poucos, provoca rupturas nas estruturas políticas tradicionais e o surgimento de novas formas de gestão.

No entanto, a crescente descrença nos mecanismos políticos tradicionais de representação e nas instituições especializadas, como os partidos políticos, para apresentar novas alternativas de ação pública tem dificultado esse progresso. Pode ser mais lenta a reversão da idéia de que os governos agem, prioritariamente, para beneficiar grupos preferenciais e ajudar a manter a coalizão de poder. Mas já é notável o reconhecimento da quebra de algumas barreiras burocráticas tanto para a obtenção de serviços rotineiros quanto para o recebimento de atenção social, como saúde e educação.

Ultimamente parece se ter reforçado a ilusão tradicional de que uma nova qualidade da decisão ou uma nova legitimidade da política pública seriam suficientes para produzir maior eficiência na administração pública. Dessa forma, não seria necessário pensar em grandes reformas administrativas porque a nova direção faria naturalmente a máquina administrativa responder com maior produtividade e qualidade. Presume-se, assim, que dificuldades administrativas anteriores são simples produto de falta de legitimidade e de apoio político mais amplo. Resolvidas essas questões por vitórias eleitorais, o resto seria decorrência natural. 
Portanto, muitos novos dirigentes chegam às posições de direção político-administrativas para se frustrar rapidamente com a máquina burocrática: redescobrem que formas tradicionais de agir e de se comportar, cultivadas secularmente, não mudam por simples reposição da liderança administrativa.

Não resta dúvida de que houve no país uma ampliação da legitimação política: novos programas sociais rompem laços de grupos preferenciais tradicionais que dominavam paternalisticamente a redistribuição de benefícios. Novos canais de distribuição de recursos sociais retiram de grupos locais tradicionais o seu poder de provedor único ou canal privilegiado de acesso ao poder. Reconhecem-se nas comunidades novas lideranças e formas de obter benefícios. Destrói-se grande parte dos sistemas locais de acesso ao poder burocrático repondo-os com novas lideranças. Pode-se argüir ser apenas uma troca de liderança, apenas a mudança de uma pessoa no poder, mantendo-se porém o mesmo caráter paternalista. De fato, parte das condições e formas tradicionais de distribuição, troca e lealdade se mantém. No entanto, vale notar a troca de liderança feita fora dos grupos tradicionais de poder. Há novas dimensões de lealdade fora do caciquismo tradicional. Há mais dificuldades de acesso e domínio dos cargos públicos locais e mais pluralidade nas pelejas políticas.

Ademais, a nova lealdade aos provedores da ação distributiva se transfere para líderes maiores não presentes na localidade e, portanto, não mais facilmente destrutíveis por novos ou antigos caciques locais. Somente novos líderes nacionais ou regionais, de igual credibilidade, poderiam, em princípio, repor essas lideranças.

A modernização efetiva do Estado somente poderá advir de formas que alterem o sistema de poder e o aglomerado político que o constitui; em outras palavras, reformas que redistribuam os recursos de poder e alterem os canais de comunicação entre o público e sua administração.

Em países em desenvolvimento, com experiências similares à brasileira, tem se verificado que as forças políticas emergentes não chegam ao poder por retração voluntária dos grupos preferenciais. Novos espaços, regras e estruturas políticas que repartam e unam novos recursos de poder são necessários para garantir a representação de novos grupos sociais. 